\title{
$1 \mathrm{eSE} \mid \begin{aligned} & \text { Revista Eletrônica } \\ & \text { dos Pós Graduandos } \\ & \text { em Sociologia Política } \\ & \text { da UFSC }\end{aligned}$
}

\section{WEBER, SCHUTZ E A BUSCA DE "SENTIDO” NA AÇÃO SOCIAL: UMA ANÁLISE COMPARATIVA ${ }^{1}$}

\section{Eliane Fioravante Garcez ${ }^{*}$}

\section{INTRODUÇÃO}

A interação, a linguagem e a comunicação, interferem e determinam o viver dos atores ao experimentar e compartilhar coisas dando sentido a elas, num ir e vir ininterrupto alicerçado em dizeres, gestos, olhares, ouvires. Esse processo os leva a operar na consciência os sentidos, as percepções, os significados, as representações do experimentado no cotidiano do Mundo da vida que, segundo Schutz (2012), abarca tanto a ação natural quanto a ação teórica.

Mas o que os leva à ação? O que envolve o "transitar" de um pensamento ao outro, de uma palavra à outra, de um projeto ao outro, de um lugar ao outro - de uma ação à outra, construindo o mundo numa sequência de agir intencional, diferentemente, portanto, de mero agir habitual?

Com base nas concepções de Edmund Husserl (1859-1938), Max Weber (18641920) e de Alfred Schutz (1899-1959)2, pode-se afirmar que muitas são as coisas

\footnotetext{
${ }^{1}$ Artigo apresentado à Disciplina Tópicos Especiais: Max Weber e a sociologia contemporânea, do Programa de Pós-Graduação em Sociologia Política da Universidade Federal de Santa Catarina (PPGSP/UFSC), ministrada pelo prof. Dr. Carlos Eduardo Sell no segundo semestre de 2013.
}

\footnotetext{
* Doutoranda no Programa de Pós-Graduação em Ciência da Informação (PPGCIN/UFSC). Mestre em Ciência da Informação (PPGCIN/UFSC). Especialista em Gestão de Bibliotecas (UDESC). Bacharel em Biblioteconomia (UFSC).

${ }^{2}$ Alfred Schutz nasceu na Áustria e faleceu em Nova York. Atuou na Primeira Guerra integrando o exército Austro-Húngaro. Em Viena (capital austríaca) estudou Direito e Ciências Sociais e publicou A construção significativa do mundo social (1932), traduzida The phenomenology of the Social World (1967). Em 1938 emigrou para Paris por conta da ameaça da invasão nazista a Áustria. Em 1939, em New
} 


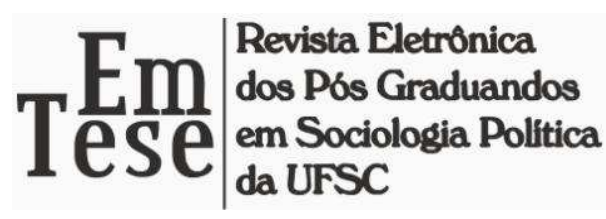

envolvidas no projeto e na condução da ação intencional. Contudo, é central no estudo da ação social o "sentido" ou a compreensão que a ação tem para aquele que a executa, para aquele(s) com quem este interage e para aquele que o(s) observa.

Segundo Schutz (2008, p. 199), "sentido" refere-se ao “[...] resultado de una interpretación de una experiencia pasada contemplada desde el Ahora con una actitude reflexiva." Portanto, o "sentido" da ação está associado à compreensão. É algo que advém da reflexão, do operado na consciência - espaço da razão. É a compreensão acerca de algo que os sentidos captam do operado pela linguagem, pela inter-relação e trocas ocorridas no cotidiano quando o ator passa a interpretar as ações 'do outro(s)', a re-interpretar as próprias ações, refazendo conceitos, "criando" o mundo das ideias e das coisas, socializando novos sentidos e significações sobre o vivido e o percebido, criando realidades, ampliando o mundo.

Estas primeiras palavras revelam a intenção de se utilizar a expressão "sentido" no título deste artigo. Ela refere-se ao sentido visado, pensado, refletido, projetado, compreendido. É o sentido representado pela linguagem discursiva, daí a importância dos postulados da interpretação subjetiva da ação de Weber e da ação intersubjetiva de Schutz.

Sendo assim, este texto tem o propósito de apresentar algumas ideias em torno das teorias da ação de Max Weber e de Alfred Schutz. Recorrendo à fenomenologia como arcabouço epistemológico e metodológico e mais precisamente à teoria do Mundo da Vida de Alfred Schutz, a pesquisa proposta tem forte vínculo com a sociologia weberiana e, por consequência, com o pensamento de Edmund Husserl.

York, passou a lecionar na Graduate Facultty of the New School for Social Research. Sempre conciliou o tempo entre estudo e atuação na área empresarial. Em solo estadunidense publicou Phenomenology and the Social Sciences. Schutz é autor de mais de trinta ensaios publicados em inglês, espanhol, alemão e francês. Ensaios póstumos foram quatro. A maior parte de seus ensaios foi publicada entre 1962-1964: Collected Papers (3 volumes). Schutz ainda colaborou na fundação da International Phenomenological Society e participou do conselho editorial da revista Philosophy and Phenomenological Research. Dedicou-se à fenomenologia, à metodologia das ciências sociais e às ideias de outros filósofos, além das de Husserl. Com sua morte, ocorrida em 1959, coube a Thomas Luckmann, seu discípulo, concluir e publicar sua última obra As estruturas do mundo da vida (SCHUTZ, 2012). 


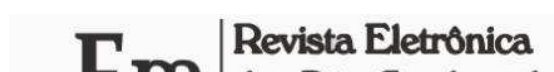 dos Pós Graduandos em Sociologia Politica da UFSC}

Para alcançar o objetivo acima citado, o tema trazido para reflexão é alinhavado em quatro tópicos. No tópico introdutório abre-se a discussão acerca da teoria do conhecimento e da teoria da ação, centrada na verstehen, sinalizando a contribuição de Husserl para o desenvolvimento das obras de Weber e de Schutz. No segundo tópico Max Weber e Alfred Schutz: aproximações teóricas sinalizam-se os pontos convergentes, divergentes e complementares entre esses dois "mundos". No terceiro tópico - $O$ "sentido" da ação: como compreendê-la? expõem-se considerações acerca da construção e emprego do recurso metodológico "tipo ideal". No quarto e último tópico, o das considerações finais, ressalta-se a complementaridade dos "mundos" de Weber e de Schutz como também a dos conhecimentos do senso comum e científico, presentes no mundo da vida, para a compreensão da ação social.

\section{WEBER E SCHUTZ: aproximações teóricas}

A preocupação de Weber e de Schutz com a Verstehen no estudo da ação social aproxima seus universos teóricos aos de Edmund Husserl. Defende Husserl (1990) que o objeto do conhecimento está na própria vivência, que não precisa ser explicada, mas compreendida. Para Weber (2012, p. 6, grifo do autor) verstehen refere-se à:

apreensão interpretativa do sentido ou da conexão de sentido: $a$ ) efetivamente visado no caso individual (na consideração histórica), ou $b$ ) visado em média ou aproximadamente (na consideração sociológica em massa), ou $c$ ) o sentido ou conexão de sentido a ser construído cientificamente (como ‘ideal-típico’) para o tipo puro (tipo ideal) de um fenômeno freqüente.

No entendimento de Schutz (2008, p. 82) o termo refere-se à "experiência de sentido comum do mundo intersubjetivo da vida cotidiana". Além de ser concebido como uma forma experimental do conhecimento de sentido comum dos assuntos 


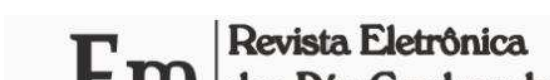

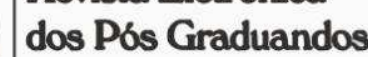

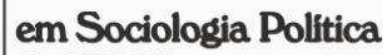 da UFSC}

humanos, o termo se refere a um problema epistemológico e um método específico das ciências sociais.

As construções que participam da experiência de sentido comum do mundo intersubjetivo da vida cotidiana são de primeiro nível, ou seja, são construções de sentido comum que se referem a elementos subjetivos da compreensão de uma ação do ator desde seu ponto de vista. Sobre essas são erguidas as construções de segundo nível das ciências sociais, ou seja, as construções científicas. Schutz (2008, p. 82) defende que se a aspiração das ciências sociais é explicar a realidade social, as construções de segundo nível "deben incluir una referencia al sentido subjetivo que tiene una acción para el actor". Vê-se aqui o imbricar do Postulado da interpretação subjetiva de Max Weber na obra de Schutz, postulado aceito na formação teórica das ciências sociais.

Partindo dessas aproximações, no item 2.1 deste tópico serão explorados o postulado da interpretação subjetiva, a tipologia da ação e os níveis da ação social, além de outros conceitos weberianos. No entanto, pela forte conexão de alguns desses fundamentos com a obra de Alfred Schutz, neste item serão resgatados ainda comentários de Schutz sobre a obra de Weber. Também neste tópico serão trazidas considerações de outros estudiosos dessa obra reconhecidamente complexa. Já no item 2.2 , repete-se o modelo desenvolvido no item 2.1, em que o foco de concentração está em Schutz, no entanto Weber o acompanha.

\subsection{WEBER E A AÇÃO NO "MUNDO" MICROSSOCIOLÓGICO}

Wolfgang Schluchter (2011, p. 3-4), estudioso da obra weberiana, comenta que apesar de colocar filosoficamente a questão do "sentido" da ação no mundo moderno e se guiar "pela questão de como esse mundo se produziu", Weber dizia pertencer não a essa área, mas à economia e à sociologia. Em sua trajetória profissional atuou como professor de economia e é considerado o fundador da sociologia. Ao defender a 


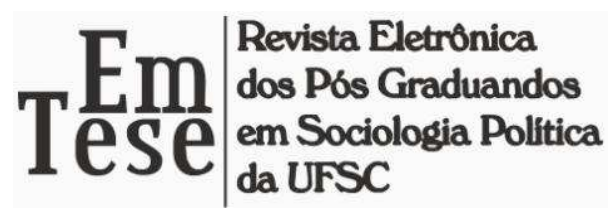

importância de se conhecer e compreender o sentido da ação social, ele anuncia a força da nova ciência.

\begin{abstract}
Para outros fins de conhecimento talvez possa ser útil ou necessário conceber o indivíduo, por exemplo, como uma associação de “células' ou um complexo de reações químicas, ou sua vida 'psíquica' como algo constituído por diversos elementos individuais (como quer que sejam qualificados). Sem dúvida, obtêm-se desse modo conhecimentos valiosos (regras causais). Contudo, nós não compreendemos o comportamento expresso em regras desses elementos. Também não compreendemos quando se trata de elementos psíquicos, e tanto menos quanto maior a precisão, no sentido das ciências naturais, com que são concebidos: jamais é este o caminho certo para chegar a uma interpretação que se baseia no sentido visado (WEBER, 2012 , p. 8, grifo do autor).
\end{abstract}

Weber (2012, p. 3) aponta a sociologia como "uma ciência que pretende compreender interpretativamente a ação social e assim explicá-la causalmente em seu curso e em seus efeitos.” Em seus estudos procurou demonstrar que todos os fenômenos do mundo sociocultural se originam da interação social e podem ser referidos a ela. Weber buscou demonstrar ainda que o papel central da sociologia é compreender o sentido que o ator designa a sua própria ação, por isso a utilização da expressão "sentido subjetivo." (SCHUTZ, 2008).

É importante ressaltar que, para Weber (2012, p. 4), não se trata “de um sentido objetivamente 'correto' ou de um sentido 'verdadeiro' obtido por indagação metafísica". Ele coloca a orientação subjetiva do ator individual no centro da análise sociológica. Dessa forma, a busca pela compreensão da ação inicia-se a partir do sujeito, daí o seu individualismo metodológico. Sobre esse método Sell (2013a, p. 111), outro estudioso da obra weberiana, assim se manifesta: "não se trata de afirmar que os indivíduos são ontologicamente racionais, mas que suas formas de ação são passíveis de compreensão racional." Segundo esse autor, foi a partir da psicologia de Karl Jaspers ${ }^{3}$ que Weber desenvolveu a sua "teoria da compreensão significativa da ação."

\footnotetext{
${ }^{3}$ Karl Theodor Jaspers, médico e filósofo existencialista alemão, nasceu em Oldemburgo (1883) e faleceu em Basileia (1969). Seu pensamento tem forte influência do seu conhecimento em psicopatologia e, em
} 


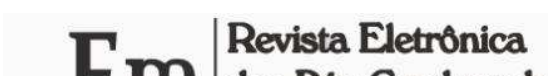

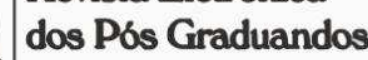 舟 da UFSC}

Em seus estudos, Weber passa a tratar de duas ordens de problemas a serem observados pelas ciências sociais: a da racionalidade na perspectiva do ator (observação de primeira ordem) e a da racionalidade na perspectiva do observador ${ }^{4}$ (observação de segunda ordem) (SELL, 2013a). Essa preocupação de Weber, conforme descreve Sell (2003a), reporta ao que expõe Schutz (2008) sobre as construções de primeiro e segundo níveis como um recurso das ciências sociais, utilizado para explicar a realidade social através do mundo intersubjetivo da vida cotidiana. No primeiro nível estão os elementos subjetivos da compreensão da ação do ponto de vista do ator e, no segundo nível, a defesa de que a ciência deve ter como referência o sentido subjetivo da ação para o ator.

Para Weber (2012, p. 3) ação é "um comportamento humano (tanto faz tratar-se de um fazer externo ou interno, de omitir ou permitir) sempre que e na medida em que o agente ou os agentes o relacionem com um sentido subjetivo.” Já a ação é social quando o "seu sentido visado pelo agente ou os agentes, se refere ao comportamento de outros, orientando-se por este em seu curso." Faz-se necessário destacar que, para Weber (2012, p. 13-14), “Os 'outros' podem ser indivíduos e conhecidos ou uma multiplicidade indeterminada de pessoas completamente desconhecidas.”

Weber (1999, p. 30, grifo do autor) enfatiza que na ação social "a conduta do agente está orientada significantemente pela conduta de outro (ou outros).” Cohn (2012, p. xiv, grifo do autor) nas páginas preliminares de Economia e Sociedade, nos esclarece que: “[...] o que conta na ação e a torna efetiva não é o seu sentido [...] mas o modo como o agente o representa para si ao conduzi-la." Observa-se que o foco está na subjetividade, na racionalidade, pois o autor afirma que uma ação tem sentido quando

parte, pelos pensamentos de Husserl e de outros filósofos. Para Jaspers "É só ao tomar consciência 'que nos tornamos livres para a investigação filosófica. Essa reflexão nos desprende de todo ser particular. Ela nos obriga a voltar de qualquer impasse em que tal saber definitivo pretendia nos paralisar. Ela nos converte'." (BARAQUIM; LAFFITTE, 2007, p. 157).

4 Refere-se a dois tipos de observador: a) àquele que faz parte do grupo, mas que não participa diretamente da ação, ou seja, omite-se conscientemente, o que de certa forma colabora para o desfecho da ação; e b) àquele que não mantém nenhum vínculo com o grupo observado. É o observador-cientista. Seu único vínculo é com a sua ciência. É também chamado de observador neutral: um "estrangeiro" (SCHUTZ, 2008; 2010; 2012). 


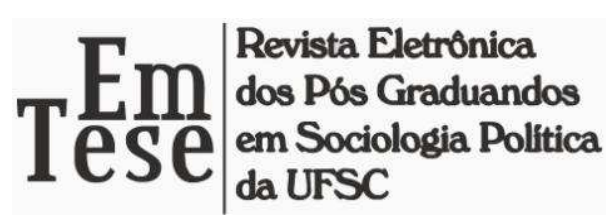

pensada, refletida. Se nenhum agente consegue pensar sem a participação ou interferência do outro, a ação é social. E aqui novamente resgata-se novamente Weber. De acordo com esse teórico, para se compreender uma ação social é preciso compreender previamente qual o sentido que a ação tem para o próprio ator, ou seja, o sentido subjetivo da ação (JONHSON, 1997).

Weber designa a compreensão como subjetiva pela proposta de buscar conhecer o "sentido" da ação para o ator em contraste ao sentido que essa mesma ação tem para seu associado ${ }^{5}$ e para aquele que a investiga (SCHUTZ, 2008).

O sentido de uma ação está associado a tudo isso. É “sentido" como sinônimo de compreensão quer pelo ator, quer por outros que com ele convive, ou para o observador social.

Após sua morte (1920), os escritos de Weber foram reunidos na obra Economia e sociedade (1921), título dado por Marianne Weber. A esse respeito, Cohn (2012, p. xiii-xv) comenta que:

o termo 'sociedade' (Gesellschaft) não exprime conceito central na terminologia weberiana, na qual é substituído nos momentos decisivos por uma expressão que designa mais propriamente as relações interindividuais constitutivas da sociedade do que esta como rede de relações já dada.

Sell (2013a, p. 12) acrescenta que é bastante provável que se estivesse vivo, Weber não fizesse uso dessa expressão no título da referida obra, por ser este um "termo que Weber sempre procurou evitar.” Esta fala remete a Elias (1994, p. 57) quando diz que: "a sociedade com sua regularidade, não é nada externo aos indivíduos [...] ela é aquilo que todo o indivíduo quer dizer quando diz 'nós'."

\footnotetext{
${ }^{5}$ É um contemporâneo, mas o termo "associado" é empregado para mencionar alguém com quem o ator compartilha as experiências do cotidiano mantendo uma relação de proximidade e de interação face a face, o que favorece o acesso aos sintomas do pensamento do outro através dos gestos, do corpo, das expressões faciais, numa relação nós (SCHUTZ, 2008, p. 46). Na concepção de Schutz, o pesquisador (um estrangeiro) tem que colocar em suspensão, ou entre parênteses, as pressuposições ontológicas do mundo natural.
} 


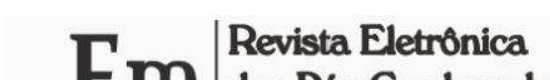

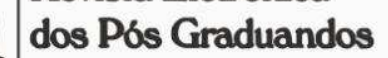

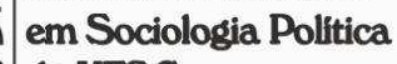 da UFSC}

\section{a) A tipologia weberiana da ação}

Max Weber insistiu na ideia de uma sociologia compreensiva capaz de decifrar os fenômenos sociais e históricos por meio de certos tipos ideais (TI) (BREDA, 2008, p. 7). Ele classificou a ação dos atores sociais em quatro tipos: racional referente a fins, racional referente a valores, afetiva e tradicional. Essa tipologia, esquematizada mais adiante, parte da ação que possui maior nível de racionalidade para a de menor nível de racionalidade e da relação que cada uma delas possui com meio, fins, valores e efeitos. Conforme Sell (2012b, 163), “a diferenciação entre [...] (os quatro tipos de ação) envolve a consideração dos diferentes graus de racionalidade presentes na própria ação."

Segundo Johnson (1997, p. 188), o grau de racionalização determinado nessa tipologia deu-se por meio das observações feitas por Weber sobre o crescimento do capitalismo industrial, da complexidade da sociedade e da vida das pessoas envolvidas cada vez mais em "princípios impessoais de cálculo racional, eficiência técnica e controle". Para esse autor, o entendimento de Weber era de que o Estado e as empresas avançariam paulatinamente no controle da vida dos indivíduos, movimento que propiciaria o aumento da burocracia. O sociólogo alemão vislumbrava que tal quadro impulsionaria um distanciamento dos laços afetivos entre os indivíduos por pressão da racionalidade requerida ao homem moderno (JOHNSON, 1997). Assim, com o desenvolvimento da modernidade, e supondo que as ações tradicionais e afetivas sofreriam mudanças a partir dessa pressão, Weber (2012, p. 15), em 1920, apresenta uma tipologia da ação classificando-a em: a) ação racional referente a fins; b) ação racional referente a valores; c) ação afetiva (alto grau de emoção/espontaneidade); e, d) ação tradicional (costume/rotinização), conforme mostrado no quadro que segue.

\begin{tabular}{|l|c|c|c|c|}
\hline \multirow{2}{*}{ AÇÃO } & \multicolumn{4}{|c|}{ RELAÇÃO } \\
\cline { 2 - 5 } & Meio & Fins & Valores & Efeitos \\
\hline
\end{tabular}




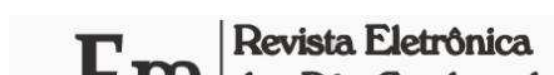 dos Pós Graduandos em Sociologia Política da UFSC}

\begin{tabular}{|l|c|c|c|c|}
\hline Racional referente a Fins & + & + & + & + \\
\hline Racional referente a Valores & + & + & + & - \\
\hline Afetiva & + & + & - & - \\
\hline Tradicional & + & - & - & - \\
\hline
\end{tabular}

Título: A tipologia weberiana da ação.

Fonte: Adaptação a partir de Sell (2013b, p. 12).

Em Economia e sociedade, Weber (2012, p. 15-16) descreve os quatro tipos de ação. O primeiro tipo é a ação orientada por regras, tendo por isso a maior chance de ser compreendida racionalmente. É determinada "por expectativas quanto ao comportamento de objetos do mundo exterior e de outras pessoas, utilizando essas expectativas como 'condições' ou 'meios' para alcançar fins próprios.” O segundo tipo é definido "pela crença consciente no valor - ético, estético, religioso ou qualquer que seja a interpretação - absoluto e inerente a determinado comportamento como tal, independentemente do resultado." O terceiro tipo é de cunho emotivo/passional. Enquadra-se aqui a ação desencadeada "por afetos ou estados emocionais atuais". O quarto tipo, o tradicional, refere-se à ação determinada "por costume arraigado", ou seja, é uma ação rotineira.

Ainda sobre essa tipologia as palavras de Weber, a partir de Sell (2013a, p. 90), são reveladoras: “nunca uma coisa é 'irracional' em si, mas sempre de um determinado ponto de vista "racional'." Sell (2012b, p. 156) argumenta que o tema racionalização assumiu tamanha relevância entre os comentadores da obra de Weber levando-os "à busca pela determinação do lugar e da função das noções de racionalidade e racionalização no esquema analítico deste autor [...]." Dentre os que entendem que a racionalização formal (com base em leis e regras) representa o conteúdo da obra weberiana, estão Arnold Eisen e Roger Brubaker. Entre os que divergem desse primeiro

\footnotetext{
${ }^{6}$ A tradução da segunda edição de Die Protestantische Ethik und der Geist der Kapitalismus: Vorbemerkung $=$ A ética protestante e o espírito do capitalismo: prefácio (WEBER, 1988, p. 35), apresentada por Sell (2013a, p. 90), instiga a pensar que a tipologia da ação de Weber é artifício metodológico para compreender modos de agir humano na ânsia de atender uma demanda desenvolvimentista do mundo moderno. Daí compreender os tipos Ação Afetiva e Ação Tradicional com menor grau de racionalidade para os fins pragmáticos requeridos pelo mundo moderno.
} 


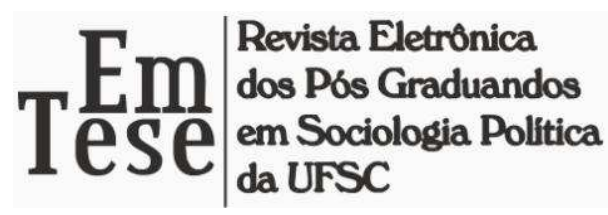

grupo, está Jürgen Habermas para quem a racionalidade estaria vinculada à racionalidade prática. Para esse autor é neste plano que o conceito weberiano (da ação) tem significado sociológico (SELL, 2012b). De acordo com Habermas (2012), a Teoria da ação de Weber se mantém distante da sua Teoria do agir comunicativo. Para Habermas isso ocorre pelo fato de Weber não explicar na teoria da ação o sentido da ação a partir de significados linguísticos. Habermas argumenta que:

[...] fundamental para ele (Weber) não é a relação interpessoal entre pelo menos dois sujeitos aptos a falar e agir - o que apontaria ao entendimento pela linguagem -, mas a atuação propositada de um sujeito solitário da ação (HABERMAS, 2012, p. 486).

Habermas (2012, p. 493) vai um pouco mais longe com sua crítica por não ver a "vontade" dos atores sendo considerada no modelo weberiano. Para ele esse modelo é centrado no subjetivo, desconsiderando elementos fundantes na relação de um ator com o outro, como a comunicação para a ação intersubjetiva (HABERMAS, 2012).

Wolfgang Schluchter (2011) também tece críticas ao modelo weberiano, por considerar que esse modelo deixa de descrever a ação afetiva e a ação tradicional. Esse "lapso" leva Schluchter a apresentar, em 1996, uma proposta alternativa para o modelo, cujo esquema é mostrado a seguir.

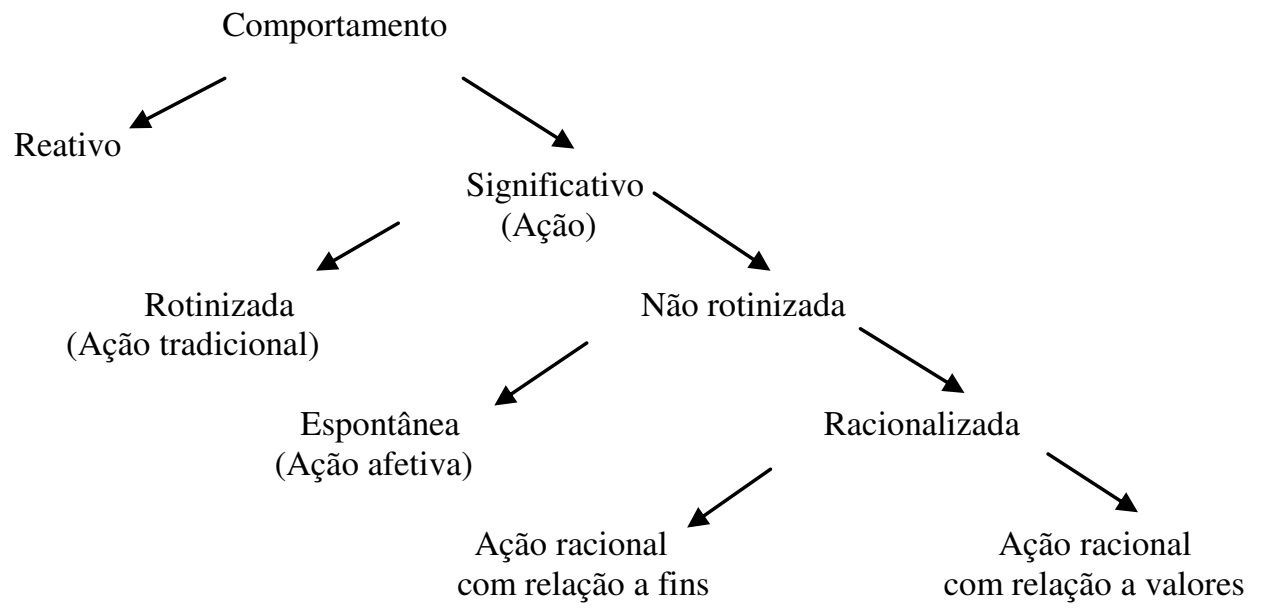




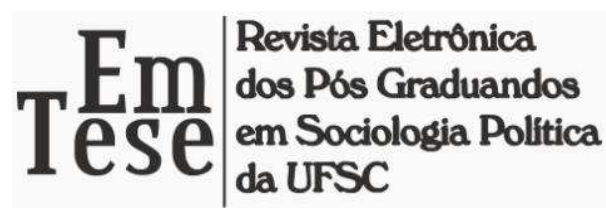

Título: Modelo esquemático das formas de ação.

Fonte: Schluchter (2010 apud SELL, 2013b, p. 16).

Esse modelo foi proposto inicialmente por Klaus Allerbeck em 1982 quando "servindo-se das indicações de Alfred Schutz, rompeu com a habitual interpretação escalar descendente atribuída a Weber.” (SELL, 2013b, p.16).

\section{b) Os níveis da análise sociológica weberiana}

$\mathrm{Na}$ sua Sociologia Compreensiva Weber previu dois níveis de análise sociológica: o nível micro e o nível macro. No primeiro nível a discussão se dá em torno do ator e da ação, portanto da relação social; no segundo nível a discussão é centrada na estrutura social, ou seja, na ordem social.

O esquema que segue, conhecido como modelo da banheira, representa como esses dois níveis, aqui denominados planos, se relacionam em três momentos: A (macro $>$ micro), B (micro>micro) e C (micro $>$ macro).

\section{PLANO MACROSSOCIOLÓGICO DA AÇÃO \\ Estrutura $=$ Ordem social $($ Coordenação da ação)}

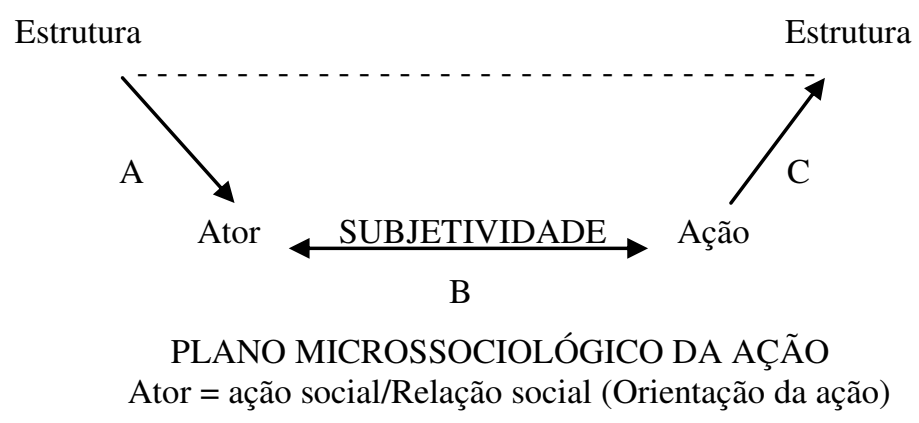

Título: Níveis de análise sociológica de Weber (Modelo da Banheira) Fonte: Adaptado a partir de Schluchter (1979 apud SELL, 2013b, p. 12).

A sociologia weberiana parte do plano microssociológico, situando nele o ator e a orientação de sua ação. A partir desse plano se desenvolve a relação social que, para Weber (2012, p. 16), refere-se ao comportamento recíproco "quanto a seu conteúdo de 


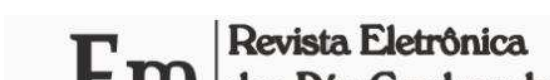

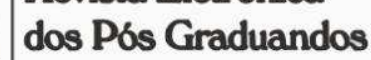

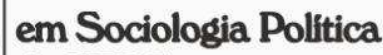 da UFSC}

'sentido' por uma pluralidade de agentes e que se orienta por essa referência." O conteúdo do sentido pode ser diversificado. Pode, por exemplo, ser de amizade ou de inimizade. Importa é que haja reciprocidade, fundamental para a sustentação da estrutura social. O plano macrossociológico representa a Ordem social. Essa ordem reúne as esferas econômica, religiosa, cultural, artística, política, erótica e intelectual que com suas normas coordenam, portanto, regulam a ação social. Para Schluchter (2012, p. 329), é justamente a transição da orientação da ação (nível micro) para a coordenação da ação (nível macro) que pressupõe o conceito de relação social.

No debate atual sobre o plano micro/macro na sociologia weberiana da ação, Sell (2012a) destaca as contribuições significativas de Schluchter e Gert Albert. Enquanto o primeiro pesquisador se atém ao plano micro, o segundo dedica-se às relações entre os dois planos. Na contestação de Schluchter está a prioridade de análise que as duas abordagens (micro e macrossociológica) dão à ação racional com relação a fins, centrada no Homo oeconomicus.

Ao tratar as discussões acerca das relações entre o nível micro e macro em estudos que abordam questões sociais da atualidade, Sell (2012a) comenta que há um predomínio de integração entre agente ou agência social (abordagem microssociológica) e estrutura ou ordem social (abordagem macrossociológica). O autor também sinaliza as discussões sobre o individualismo e o holismo metodológicos - nas modalidades radical e moderado -, e "uma terceira via", a do equilíbrio entre um e outro método.

\subsection{SCHUTZ E A AÇÃO NO "MUNDO DA VIDA"}

Neste subtópico apresenta-se parte da trajetória do estudioso Alfred Schutz entrecruzada com as ideias de Weber e com a fenomenologia transcendental de Husserl.

Um ano após ser publicada Economia e Sociedade, portanto em 1922, Schutz começa a estudá-la. De 1924 a 1928 dedica-se à fundamentação dos conceitos utilizados por Weber. Segundo Correia (2005, p. 27), o entendimento de Schutz era "que o 


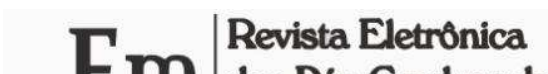

trabalho do sociólogo partia de suposições carentes de fundamentação, o que seria explicado pela falta de interesse pelos problemas epistemológicos fundamentais que não se relacionassem de modo directo com as questões sociológicas." Schutz também tece críticas ao postulado weberiano da interpretação subjetiva - para a construção de modelos científicos do mundo social, pois discorda de a subjetividade ser a única a ser considerada pelo sociólogo alemão no estudo da ação (CORREIA, 2005).

No intuito de tornar claros os conceitos de sentido, ação e intersubjetividade, dentre outros, Schutz vai se aproximando cada vez mais da obra de Husserl e de seu método de retorno à experiência e à descrição.

Sem aprofundar aqui questões conceituais, para Schutz, o postulado da interpretação subjetiva (weberiano), de abordagem schutziana, o postulado da coerência lógica e o postulado da adequação, são fundamentais para se obter um método científico consistente para as ciências sociais. Esse autor defende que com esses três postulados é possível captar de maneira objetiva o sentido subjetivo da ação humana, o sentido comum dessas ações na vida cotidiana.

Ao concluir a análise da obra de Husserl, Schutz propõe uma compreensão da ação social a partir da atitude natural do sujeito situado no Mundo da vida $=$ Lebenswelt . Também denominado Mundo da vida cotidiana, esse é o mundo da atitude natural, da relação entre semelhantes, da existência cotidiana, da experiência do pensamento do senso comum, mundo natural, social e cultural, mundo de trocas, portanto intersubjetivo, em que é preciso entender fundamentalmente os que estão mais próximos (os associados) e ser compreendido por eles. Ou ainda, conforme Schutz e Luckmann (2003, p. 27), mundo que “[...] no solo actuamos y operamos dentro del [...] sino también sobre él." Como enfatiza Schutz (2008, p. 74), esse mundo "supone la intercomunicación y el lenguaje." Com essas ideias, onze anos após a publicação de Economia e sociedade, Schutz coloca o Mundo da vida em evidência ao publicar $A$ construção significativa do mundo social (1932).

Em 03 de maio de 1932, Husserl escreve uma carta à Schutz, na qual registra o reconhecimento pelo seu trabalho sério e completo. Para Husserl, Schutz foi um dos 


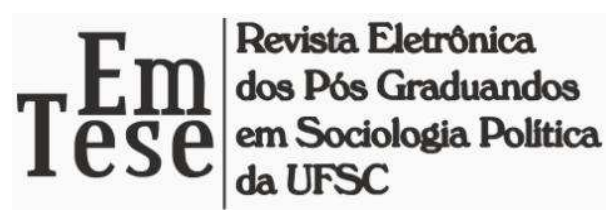

poucos a alcançar o significado mais profundo de sua obra (BREDA, 2008, p. 8). De acordo com Correia (2005, p. 12-13), o respeito e atenção obtidos por Schutz tornam-no "um correspondente privilegiado e um interlocutor de Edmund Husserl" até 1938, quando esse teórico veio a falecer.

Observa-se que, diferentemente de Weber, Schutz entendia que o conhecimento não é uma questão individual, e sim intersubjetivo e socializado, pois no Mundo da vida a atitude antes de ser teórica é natural (pré-teórica). Assim, a chave para a compreensão do conhecimento humano está em atentar-se para o Mundo da vida e diante desse mundo o pesquisador deve ter uma "atitude desinteressada" (SCHUTZ, 1953, p. 7).

Schutz discorda da figuração da ação afetiva e da ação tradicional na tipologia apresentada por Weber por entender que a ação precisa de um propósito interno antes de ser exteriorizada pelo ator. Faz referência aos conceitos de epoché ou redução fenomenológica ${ }^{7}$ (Husserliano), intencionalidade (husserliano) e causalidade (weberiano) da Teoria da Ação. ${ }^{8}$ Para Husserl (1980, p. viii) a consciência é intencionalidade dirigida a alguma coisa, e a intencionalidade é "uma atividade constituída por atos (percepção, imaginação, especulação, volição, paixão, etc.), com os quais visa algo." Para Schutz (2012, p. 436) "um ato intencional é qualquer ato no qual e pelo qual uma pessoa experiência um objeto, seja ele físico ou ideal. Por meio dele o próprio objeto é cognitivamente constituído." Diante dessas considerações, aqui cabe a pergunta: o que Schutz entende por ação e por comportamento?

\footnotetext{
'Comportamiento' se refiere a todo tipo de experiencias espontáneas subjetivamente providas de sentido, sean las de la vida interior o las que se insertan en el mundo externo. [...] El comportamiento ideado de antemano, es decir, basado en un proeycto preconcebido, será llamado acción con independencia de que sea manifiesto o latente (SCHUTZ, 2008, p. 200).
}

\footnotetext{
${ }^{7}$ Princípio husserliano que orienta o pesquisador social. Segundo Chauí (1980, p. XI), “é a operação pela qual a existência efetiva do mundo exterior é 'posta entre parênteses', para que a investigação se ocupe apenas com as operações realizadas pela consciência." A suspensão da crença é fundamental na busca de novos sentidos/essências, ou da essência do fenômeno estudado.

${ }^{8}$ Segundo Johnson, (1997, p. 111), a Teoria da Ação trata das “[...] rotinas diárias, interações e eventos aceitos como coisas naturais e consideradas não só como origem da experiência individual, mas também das formas assumidas por grupos ou sociedades."
} 


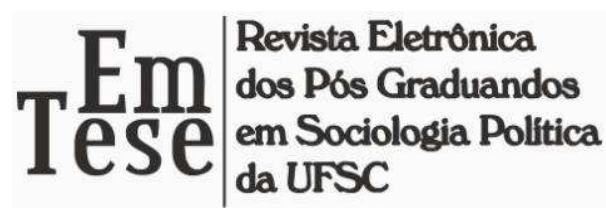

Como se vê, para esse autor comportamento está relacionado à experiência espontânea e à ação ao projeto preconcebido. Então, como se dá o desencadear de comportamento à ação?

Para Schutz há dois tipos de comportamento: a) comportamento latente e b) comportamento manifesto. $\mathrm{O}$ comportamento latente refere-se ao mero pensar, portanto integra o mundo interno do ator. É dividido em dois: comportamento latente com propósito e comportamento latente sem propósito. $\mathrm{O}$ primeiro desses dois quando colocado em prática é uma ação denominada efetuação; quando não colocado em prática é mera fantasia. O comportamento manifesto trata-se do mero fazer. É o explicitado no mundo externo - a ação em si, ou seja, também uma efetuação. Assim, há duas origens da ação por efetuação. Uma advinda do comportamento latente provido de propósito e outra do comportamento manifesto. Para diferenciá-las, Schutz, denomina a segunda de execução (SCHUTZ, 2008). Essas ideias podem ser esquematizadas da seguinte forma:

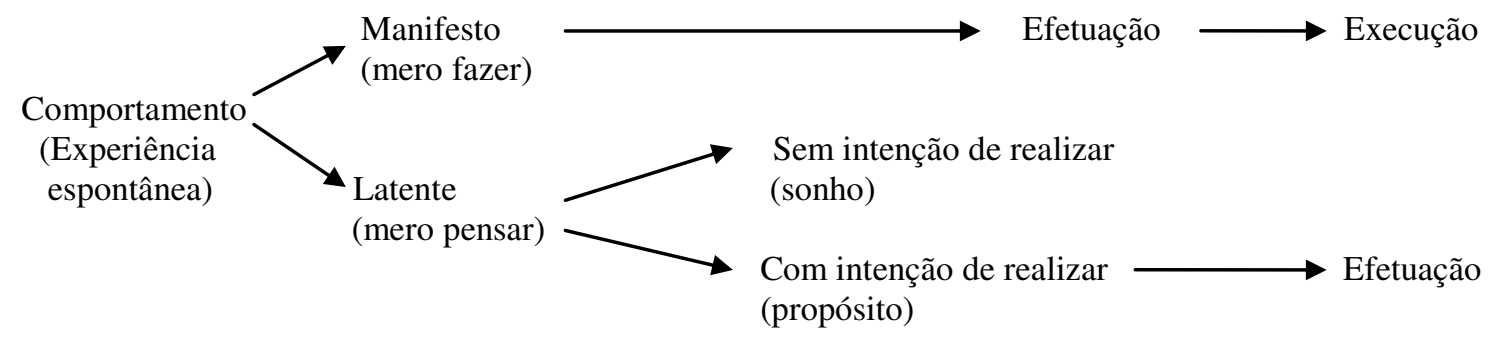

Título: Tipos de comportamento e de ação na perspectiva schutziana.

Fonte: Da autora a partir de Schutz (2010, p. 48, 200-201).

O sentido da ação difere para o ator, seu associado e para o observador. Portanto, no sentido da ação estão envolvidos níveis de distanciamento/envolvimento, interação e propósito. É importante fazer tal distinção pelas consequências que essas posições trazem para a compreensão da ação (SCHUTZ, 2008).

Em Tese, Florianópolis, v. 11, n. 1, jan./jun., 2014. ISSN: 1806-5023 


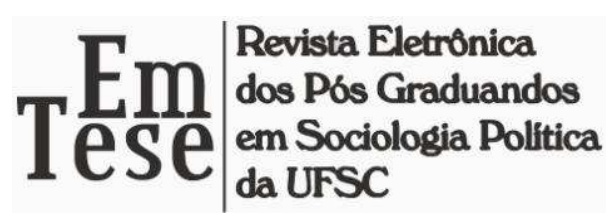

primero, que en el pensamiento de sentido común sólo tenemos la posibilidad de comprender la acción del Otro de manera suficiente para nuestro propósito a mano; segundo, que, para aumentar esta posibilidad, debemos investigar el sentido que tiene la acción para el actor (SCHUTZ, 2008, p. 52).

Em Schutz há reconhecimento do Postulado da interpretação subjetiva, no entanto, como mencionado em outros pontos deste artigo, ele não o aceita por inteiro. Para esse autor, "subjetiva" é "la infortunada expresión”. Schutz (2008, p. 53) refere-se ao postulado como "una particularidad de la sociología de Max Weber ni de la metodología de las ciencias sociais en general, sino un principio de la construcción de tipos de cursos de acción en la experiencia de sentido común."

Apesar de preferir fazer uso do termo "comportamento" no lugar de "conduta" por esse último abarcar manifestações espontâneas não providas de sentido, como os reflexos -, Schutz (2008, p. 55) classifica três tipos de conduta: sensata, razoável e racional. Aqui dá-se destaque a uma fala sua sobre conduta racional (por considerar-se que esse recorte expressa a divergência de entendimento de Schutz com a tipologia weberiana da ação): "la determinación de la acción, en términos afectivos o en términos tradicionales, es [...] incompatible con este tipo.”

O tempo e o espaço são outros aspectos que interferem no sentido e determinação de uma ação. De acordo com Schutz (2008), apenas as experiências providas de sentido podem ser lembradas e questionadas quanto aos motivos de sua constituição. O teórico também cita a "situação biograficamente determinada" do ator, suas experiências prévias, o acervo de conhecimento que possui diante de si para uso e as escolhas que faz. Schutz (2008, p. 93) acrescenta que aquilo que constitui o propósito de um ator para uma ação futura se relaciona a "las experiencias que yo, el actor, tengo de mi situación biograficamente determinada en el momento en que elaboro cualquier preyecto.” A situação biográfica somada à experiência que o ator possui no espaço, no tempo e na sociedade o faz perceber que nessa experiência há elementos que lhe são impostos, há outros que ele controla ou pode controlar e por isso há elementos que podem ser modificados por ele (SCHUTZ, 2008). 


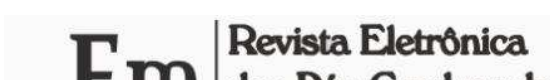

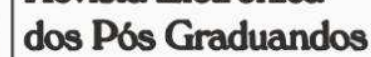 mostomantas da UFSC}

\section{O "SENTIDO" DA AÇÃO: como compreendê-la?}

Com que artifício metodológico o cientista social vai a campo buscar compreender um fenômeno? Como captará o pensamento de um ator relacionado à ação do outro? Que salvaguarda esse observador precisa ter para manter-se distante da cena, captar as essências contidas nas ações e interpretá-las, ou melhor, com quais artifícios metodológicos poderá compreender o sentido subjetivo de uma ação por meio de ações objetivas? As orientações de Weber e Schutz nessa empreitada são para a "construção" e aplicação de um tipo ideal (TI).

De uso exclusivo das ciências da ação e proposto por Max Weber, esse recurso metodológico se refere a um conceito pré-estabelecido pelo pesquisador antes de ir a campo, servindo-lhe como guia, ou parâmetro, para que algo desconhecido passe a ser conhecido.

Conforme Weber (apud SCHLUCHTER, 2011, p. 33), o tipo ideal (TI) é "una imagen intelectual [...] que contiene el significado de un concepto limítrofe puramente ideal, a partir del cual se miede la realidad para explicar determinados componentes significativos de su contenido empírico; con el cual es comparada la realidad." Jonhson (1997, p. 240) comenta que esse modelo abstrato é utilizado pelo pesquisador para observar "aspectos do mundo real de uma forma mais clara e mais sistemática." Complementa o autor que esse modelo não serve para "descrever ou explicar o mundo. Em vez disso, fornece-nos pontos de comparação a partir dos quais podemos fazer as nossas observações. [...] são ideais apenas no sentido em que são puros e abstratos, não no sentido mais comum de serem desejáveis ou bons." Nas palavras de Tore Lindbekk (1992, apud SÁNCHEZ DE PUERTA TRUJILLO, 2006, p. 14), um tipo ideal ou um conjunto deles, serve para três fins: “[...] llegar a un lenguaje común a la hora de hablar o escribir sobre un concepto sociológico. [...] compararlos con realidades empíricas para obtener conclusiones. [...] (y) para la formulación de hipótesis." Fazendo uma síntese 


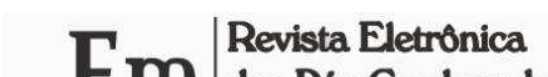

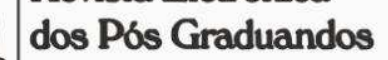

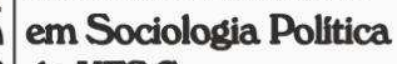 da UFSC}

desse recurso metodológico, Schutz (2012, p. 315) expõe que o modelo TI é um "esquema interpretativo de ações concretas reais."

Nota-se que não se trata de um "conceito" intuído pelo pesquisador, e sim de um recurso pautado na racionalidade. Contudo, o que o observador científico deve considerar para construir esse "guia"? Quais as proposições de Weber e de Schutz quanto à construção e aplicação do esquema?

Considerando que as proposições desses pesquisadores estão associadas, imbricadas, entrelaçadas, e considerando ainda o interesse particular da autora pela fenomenologia de Alfred Schutz, no próximo subtópico será explorada sua proposta tipificadora da ação e personalidade do ator fictício - o homúnculo -, por representar uma visão mais alargada e ao mesmo tempo mais verticalizada para se compreender o sentido da ação social. Ressalta-se que as ideias apresentadas por Schutz estão alicerçadas em Weber e Husserl. Ao apossar-se delas Schutz as questiona, as aprimora e com isso avança.

Segundo Schutz (2012, p. 296-297), “os constructos envolvidos no mundo da experiência do senso comum a respeito do mundo intersubjetivo da vida cotidiana" são a base para os constructos das ciências sociais. Como no mundo vivido, no senso comum encontram-se elementos subjetivos e os constructos advindos desses elementos. Esses estão também a serviço do cientista social e devem igualmente basear-se na compreensão. Ainda, segundo Schutz (2012, p. 296-297), “são constructos típico-ideais objetivos [...] são sistemas teóricos que possuem hipóteses gerais e passíveis de verificação." Para se chegar a eles é preciso desenvolver dispositivos metodológicos capazes de compreender objetivamente algo subjetivo. Nesse "mergulho controlado" o cientista deve assumir uma postura de mero observador orientado apenas pelo corpus de sua ciência e por um método científico.

Segundo Schutz (2012, p. 299), “o problema científico, uma vez estabelecido, determina sozinho a estrutura de relevâncias. [...] Portanto seu sistema de relevâncias que serve como esquema para sua seleção e interpretação é determinado pela atitude científica." Ainda de acordo com Schutz (2012, p. 300), o problema científico possui 


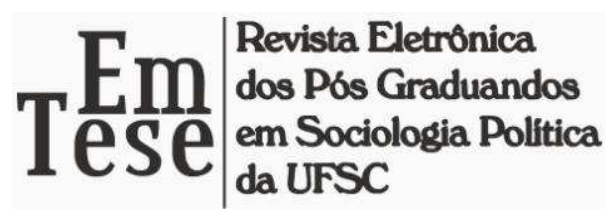

duas funções: a) determinar "os limites criando o domínio do objeto científico com os quais todos os conceitos devem ser compatíveis; b) criar um esquema referencial para a construção de todos os tipos ideais que podem ser considerados relevantes."

Para a construção dos conceitos da ação humana, Schutz (2012, p. 300) apresenta três postulados: a) postulado da consistência lógica (para estabelecer os constructos típicos o cientista deve buscar o maior grau de clareza e precisão possíveis relacionados ao fundamento conceitual e ficar atento aos princípios da lógica formal); b) postulado da interpretação científica (o cientista precisa ficar atento ao modelo de mente a ser construído e seus conteúdos (a construção do homúnculo), pois é a partir dessa mente que os fatos observados poderão ser explicados); c) postulado da adequação (cada termo do modelo construído da ação humana deve ser compreendido pelo ator e seus semelhantes situados no mundo da vida). Schutz (2012) parte do pressuposto que

[...] todos os modelos das ciências que são adequadamente construídos - não apenas os das ciências sociais - são racionais. [...] ao construir um modelo de uma consciência fictícia, o cientista pode selecionar como relevante para seu problema apenas aqueles elementos que tornam possíveis ações e reações racionais por parte de seus homúnculos (SCHUTZ, 2012, p. 301-302).

A utilidade de modelos científicos de padrões racionais, portanto de comportamentos racionais, deve seguir o postulado da racionalidade, que pode ser assim formulado: o curso da ação e os tipos pessoais ao serem construídos precisam considerar que o ator no mundo da vida seria capaz de realizar a ação tipificada, caso tivesse um conhecimento claro e distinto de todos os elementos que o cientista assume como relevantes para essa ação.

Dentre as vantagens para uso de tais modelos estão: a) esses padrões de comportamento racional padronizado podem ser estudados de forma isolada; b) é um comportamento supostamente previsível (dentro do que foi tipificado no constructo) diferentemente daquele dos indivíduos na vida social, portanto servem para averiguar comportamentos desviantes no mundo real; e, c) a partir de algumas variações, esses 


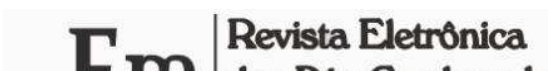

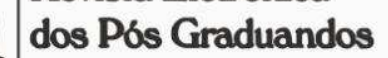

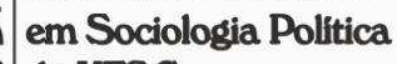 da UFSC}

modelos servem para resolver o mesmo problema científico, por ser meramente um locus de implicações (SCHUTZ, 2012, p. 303). Segundo o autor, os TI da conduta subjetiva tornam-se fundamentais porque "queremos compreendê-los, e isso só é possível no âmbito de um esquema dos motivos humanos, dos meios e fins humanos, do planejamento humano, em suma, das categorias da ação humana.” Para alcançar tal intento, o cientista social deve "perguntar o que acontece na mente de um ator individual cujo ato levou ao fenômeno em questão."

A compreensão que se tem do comportamento dos outros ocorre em termos de TI. O processo pode ser assim descrito: ele é extraído de uma parte da experiência identificada ou reconhecida em outra pessoa; uma sintese de reconhecimento como prefere nomear Schutz. O TI pode ser classificado em: a) tipo ideal pessoal: refere-se ao TI de uma pessoa que se expressa ou se expressou de determinada maneira, b) tipo material ou tipo de curso da ação: o TI do próprio processo expressivo, ou mesmo os resultados exteriores interpretados como sendo os signos do processo expressivo. Os dois tipos estão imbricados, já que o tipo ideal pessoal é derivado do curso da ação, ou seja, o pesquisador precisará conhecer antecipadamente o trabalho ou atividade do ator real (SCHUTZ, 2012, p. 306).

Considerando a fala de Schutz (2012, p. 307) de que "é só agindo que pode existir um ato", pode-se dizer que ao procurar compreender o comportamento do outro de modo típico ideal o cientista terá diante de si um método dual. Ele pode iniciar a compreensão pelo ato concluído, determinar o tipo de ação que o produziu e estabelecer o tipo de pessoa que agiu daquele modo, ou fazer o processo inverso - partir do conhecimento do tipo ideal pessoal (homúnculo, fantoche ou boneco), e, então, deduzir o ato correspondente. Schutz ainda enfatiza a compreensão que o intérprete precisará fazer quanto à percepção do ato manifesto de outra pessoa para descobrir os motivos com-a-finalidade-de ou motivos-porque por trás do ato. Criado a partir de métodos racionais, para Schutz (2012, p. 308) “o ator típico ideal nunca passa pela experiência de escolher ou preferir alguma coisa à outra.” 


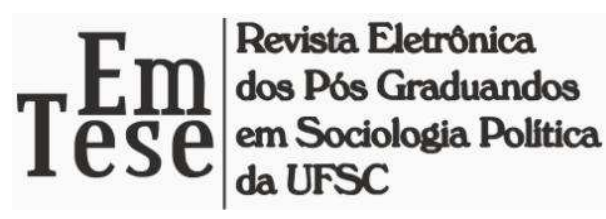

\begin{abstract}
A técnica de construir tipos ideais pessoais consiste em postular pessoas que podem ser motivadas pelo tipo ideal material já definido. [...] o que é abstratamente definido como a unidade do ato ou da ação vista pelo observador é abstraída e, portanto a unidade do ato de outra pessoa depende do ponto de vista do observador, o que por sua vez irá variar conforme seus interesses e seus problemas. [...] Portanto, o próprio tipo ideal pessoal é determinado pelo ponto de vista do intérprete. Ele é uma função da própria questão que ele busca responder (SCHUTZ, 2012, p. 309, grifo do autor).
\end{abstract}

Sendo assim, o tipo ideal pessoal depende do seu criador que define quando "nasce", como "vive" e quando "morre" (SCHUTZ, 2012). O "conhecimento" que o homúnculo possui lhe foi imposto pelo pesquisador com o objetivo de realizar o trabalho para o qual foi trazido à "vida" no mundo científico - o problema científico do investigador. Esses "bonecos" não estão soltos no mundo social. Eles não têm vida própria, são abstrações com base nos constructos da ciência do seu criador e de um ponto de vista através do qual esse cientista olha para o mundo social.

Para explicar como se dá a aplicação de um modelo TI, será utilizado do mundo concreto, a título de exemplo, o ator-aluno da educação básica. Tal escolha se deve ao interesse da autora em compreender qual o "sentido" da ação desse ator relacionada ao objeto de estudo investigado na Ciência da Informação.

Primeiramente o pesquisador "dá" ao homúnculo uma série de características e vincula a elas uma série de ações típicas. Após definir a consciência fictícia e demais características do ator-aluno típico ideal e as ações típicas correspondentes, essas serão aplicadas a "n" alunos concretos. A partir daí a primeira afirmação a ser feita ao aplicar o modelo ideal típico a um aluno concreto é de que "n" é um aluno típico e, sendo um aluno típico, deduz-se que ele frequenta a escola diariamente. E assim, uma a uma, todas as ações típicas dadas ao "boneco" aluno pelo pesquisador passam a ser averiguadas. Se o ator-aluno (real) "n" realiza a ação típica "a" do rol das ações descritas pelo pesquisador ao modelo tipo ideal, logo, pode-se afirmar que "n" é um aluno típico. A confirmação de uma ação típica ideal sendo realizada pelo ator-aluno real é relevante para a previsão de ações futuras relacionada ao objeto estudado (SCHUTZ, 2012). 


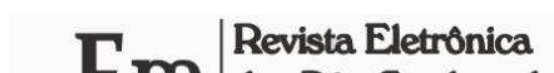 dos Pós Graduandos em Sociologia Politica da UFSC}

Schutz nos alerta que se o ator real não realizar o ato previsto no homúnculo, o pesquisador precisará esquematizar outro TI a fim de tornar compreensíveis as ações estudadas.

Se a pessoa não realiza o ato tal como previsto, precisamos assumir que aplicamos um tipo ideal errado à pessoa em questão. Então temos que buscar outro tipo ideal pessoal que poderá tornar sua ação compreensível (SCHUTZ, 2012, p. 316, grifo do autor).

A liberdade, ou a não liberdade, que o ator-aluno " $n$ " tem de realizar suas ações o faz aproximar-se mais ou menos do homúnculo. Quanto menos liberdade tem o ator real, mais próximo estará do homúnculo e, portanto, mais fiel será o resultado da pesquisa relacionada à compreensão da ação investigada. Por isso a metodologia para a construção de um modelo TI, criado por Schutz, perpassa pelo entendimento prévio ou familiaridade que o pesquisador social tem sobre o operado no Lebenswelt.

\section{CONSIDERAÇÕES FINAIS}

Com este texto buscou-se apresentar uma análise comparativa entre os preceitos e/ou preocupações teóricas de Weber e de Schutz relacionados à ação. O primeiro teórico dedicou-se a discutir como o cientista pode captar o significado que uma ação tem para o ator social (subjetividade). O segundo buscou entender como dois atores podem captar o sentido da ação de um de outro (intersubjetividade).

Correia (2005, p. 14) nos fala que o debate de Schutz sobre a epistemologia das ciências "centrava-se nas relações entre a formulação científica de conceitos e as construções mentais originárias do mundo da vida quotidiana." Nesse laboratório social vivo ${ }^{9}$ o pesquisador se utiliza do tipo ideal (TI) como instrumento para que o sentido de

\footnotetext{
${ }^{9}$ Expressão de Serge Moscovici (2004), para quem é impossível se aproximar do que de mais real existe sobre determinado objeto, ou pensamento dos indivíduos, sem estudá-los no seu cotidiano, ou seja, no seu Laboratório social vivo.
} 


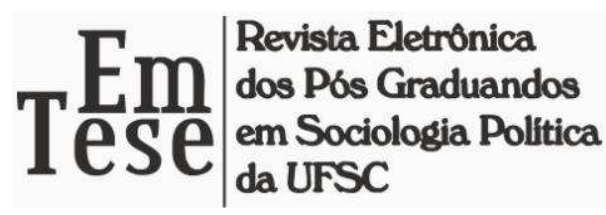

um fenômeno latente no mundo da vida possa ser compreendido objetivamente. A sua condição de estrangeiro o impede de manter uma relação intersubjetiva com os atores envolvidos com a ação por ele estudada. Dessa ausência de cumplicidade os atores do grupo observado passam a compreender o pesquisador como a-histórico. Não convivendo com os atores investigados, o cientista não compartilha com eles o seu mundo natural nem teórico. Na tipologia weberiana a ação do pesquisador é a mais racional, há meios, fins, valores e efeitos. Numa concepção schutziana essa ação, também racional, possui motivos-para e motivos-porque, ou um comportamento latente cujo propósito culminou numa efetuação.

Por fim, retoma-se a questão do sentido da ação e a imbricação desse sentido com o mundo teórico e o mundo pré-teórico. A ciência dá sentido às coisas, sentido que pode ser designado como de segunda instância. $\mathrm{O}$ de primeira instância é dado pelos que convivem cotidianamente com essas coisas. Contudo, para conhecer o sentido que determinado grupo ou ator social dá as coisas recorre-se à ciência. É ela que interpreta aquilo que está sempre em processo de conhecer e de compreender, condição semelhante a do homem.

\section{REFERÊNCIAS}

BARAQUIM, Noëlla; LAFFITTE, Jaqueline. Dicionário universitário dos filósofos. Tradução de Eduardo Brandão. São Paulo: Martins Fontes, 2007.

BREDA, H. L. van. Prólogo. In: SCHUTZ, Alfred. El problema de la realidad social: escritos I. Compilado por Maurice Natanson. Tradução de Néstor Míguez. 2. ed. Buenos Aires: Amorrortu, 2008. (Biblioteca de Sociologia).

CHAUÍ, Marilena de Souza. Husserl (1859-1938): vida e obra. In: HUSSERL, Edmund. Investigações lógicas: sexta investigação (elementos de uma elucidação fenomenológica do conhecimento). São Paulo: Abril Cultural, 1980. (Os pensadores). 


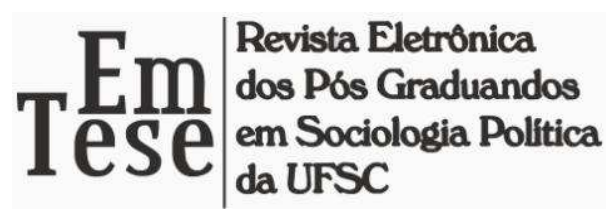

COHN, Gabriel. Alguns problemas conceituais e de tradução em Economia e sociedade. In: Economia e sociedade: fundamentos da sociologia compreensiva. Tradução de Régis Barbosa e Karen Elsabe Barbosa. Revisão técnica de Gabriel Cohn. 4. ed. Brasília: Editora Universidade de Brasília, 2012. v.1. p. xiii-xv.

CORREIA, João Carlos. A teoria da comunicação de Alfred Schutz. Lisboa: Livros Horizonte, 2005. (Media e Jornalismo).

ELIAS, Norbert. A sociedade dos indivíduos (1939). In:__. A sociedade dos indivíduos. Tradução de Vera Ribeiro. Rio de janeiro: Jorge Zaher, 1994. p. 11-60.

HABERMAS, Jürgen. Primeira consideração intermediária: agir social, atividade teleológica e comunicação. In: Teoria do agir comunicativo: racionalidade da ação e racionalização social. 1. ed. São Paulo: Martins Fontes, 2012. v. 1, p. 476-581.

HUSSERL, Edmund. A ideia da fenomenologia. Tradução de Artur Morão. Edições 70: (Brasil), 1990. (Textos filosóficos, 8).

Investigações lógicas: sexta investigação (elementos de uma elucidação fenomenológica do conhecimento). São Paulo: Abril Cultural, 1980. (Os pensadores).

JONHSON, Allan G. Dicionário de sociologia: guia prático da linguagem sociológica. Rio de janeiro: Jorge Zahar, 1997.

MOSCOVICI, Sérge. Representações sociais: investigações em psicologia social. 2. ed. Petrópolis (RJ): Vozes, 2004. (Coleção Psicologia Social).

SÁNCHEZ DE PUERTA TRUJILLO, Fernando. Los tipos ideales en la práctica: significados, construcciones, aplicaciones, Empiria: revista de metodologia de ciências sociales, Madri (Espanha), n. 11, ene./jun., 2006, p. 11-32. Disponível em: <http://www.redalyc.org/articulo.oa?id=297125210001>. Acesso em: 12 nov. 2013.

SCHLUCHTER, Wolfgang. Acción, orden y cultura: estudios para un programa de investigación en conexión con Max Weber. Prometeo: Buenos Aires, 2011, p.19-54.

Epílogo: ação, ordem e cultura. In: - Paradoxos da modernidade: cultura e conduta na teoria de Max Weber. Tradução de Roberto Leal Ferreira. 1. ed. São Paulo: Unesp, 2012. p. 325-330.

SCHUTZ, Alfred. O estrangeiro: um ensaio em psicologia social. Tradução de Márcio Duarte e Michael Hanke. Revista Espaço Acadêmico, v. 10, n. 113, p. 117-129, out., 2010.

Disponível

em: 


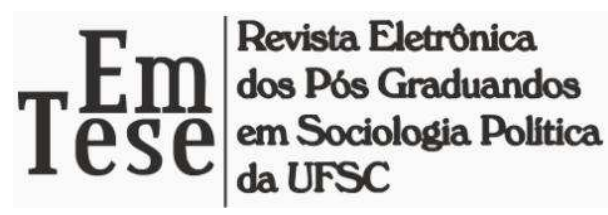

<http://www.periodicos.uem.br/ojs/index.php/EspacoAcademico/article/view/11345/61 53>. Acesso em: 16 abr. 2013.

Senso-comum e a interpretação científica da ação humana. [1953]. 39 p.

Disponível em:

$<$ http://mailattachment.googleusercontent.com/attachment/?ui=2\&ik=e15e73dd25\&view=att\&th=1 3d5977bec41889c\&attid=0.1\&disp=safe\&realattid=f_hdz5k1g30\&zw\&saduie =AG9B $\underline{\text { P-4TcDPdXZejFLecCkZ7sop\&sadet=1366906371223\&sads=HXgs8D3BmbTR- }}$ SUt9XpB3kB0xgc>. Acesso em: 12 mar. 2013.

El problema de la realidad social: escritos I. Compilado por Maurice Natanson. Tradução de Néstor Míguez. 2. ed. Buenos Aires: amorrortu, 2008. (Biblioteca de Sociologia).

. Sobre fenomenologia e relações sociais. Edição e organização de Helmut T. R. Wagner. Tradução de Raquel Weiss. Petrópolis (RJ): Vozes, 2012. (Coleção Sociologia).

SCHUTZ, Alfred; LUCKMANN, Thomas. Las estructuras del mundo de la vida. 1. ed. Buenos Aires: Amarrortu, 2003. (Biblioteca de Sociologia).

SELL, Carlos Eduardo. Max Weber e a racionalização da vida. Petrópolis (RJ): Vozes, 2013a.

O nascimento da sociologia weberiana: sobre algumas categorias da sociologia compreensiva 100 anos depois. Paper inscrito no GT 34 Teoria Sociológica para o XVI Congresso Brasileiro de Sociologia, Salvador, set. 2013b.

Um paradigma weberiano?: anotações sobre um programa de pesquisa. ENCONTRO ANUAL DA ANPOCS, 36, 21 a 25 out. 2012, Águas de Lindóia (SP). GT 24 - O Pluralismo na teoria social contemporânea. 2012a. Disponível em: $<$ http://portal.anpocs.org/portal/index.php?option=com_docman\&task=doc_view\&gid= 8108\&Itemid=217> . Acesso em: 14 jan. 2014.

. Racionalidade e racionalização em Max Weber. Rev. Bras. Ciências Sociais, [São Paulo], v. 27, n. 79, p. 153-233, jun. 2012b.

WEBER, Max. Sociologia. Organizado por Gabriel Cohn. 7.ed. São Paulo: Ática, 1999. (Grandes Cientistas Sociais, 13).

Conceitos sociológicos fundamentais. In:__. Economia e sociedade: fundamentos da sociologia compreensiva. Tradução de Régis Barbosa e Karen Elsabe

Em Tese, Florianópolis, v. 11, n. 1, jan./jun., 2014. ISSN: 1806-5023 


\section{Em Revista Eletrônica dos Pós Graduandos \\ eSe em Sociologia Política da UFSC}

Barbosa. Revisão técnica de Gabriel Cohn. 4. ed. Brasília: Editora Universidade de Brasília, 2012. v.1, part 1, cap. 1, p. 3-35. 


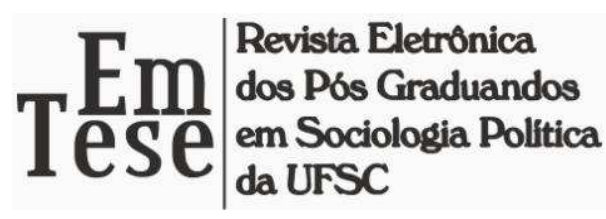

\section{RESUMO}

O artigo discorre sobre as teorias de Max Weber e de Alfred Schutz e a aproximação desses mundos teóricos com a fenomenologia do filósofo Edmund Husserl. No texto são explorados os conceitos de sentido, compreensão, ação, ação social, relação social dentre outros. São apresentados também a tipologia da ação e os dois níveis de análise sociológica (microssocial e macrossocial) na concepção de Weber, para quem a ação é fruto da subjetividade. Já para Schutz, a ação é intersubjetiva, socializada e a compreensão está por detrás da ação, quer para o sentido que o ator dá a sua própria ação (subjetivo), quer para a ação de seu semelhante (intersubjetivo). Tendo em vista essas teorias, este trabalho apresenta os pontos divergentes e convergentes entre elas, mas acima de tudo, registra o quanto são complementares na busca de compreensão do sentido da ação social. Além dos preceitos conceituais, o texto discute a construção e a aplicação do modelo "tipo ideal” (TI) amparados numa concepção schutziana.

PALAVRAS-CHAVE: Ação social - sentido. Max Weber - Sociologia compreensiva. Alfred Schutz - Fenomenologia compreensiva - Mundo da vida. Tipo ideal.

\begin{abstract}
The article discusses the theories of Max Weber and Alfred Schutz and the theoretical approach of these worlds with the phenomenology of philosopher Edmund Husserl. In the text are explored concepts of meaning, understanding, action, social action, social relation among others. The type of action and the two levels of sociological analysis (micro-and macro-) in designing Weber, for whom the action is the result of subjectivity are also presented. Have Schutz, action is intersubjective, socialized and understanding is behind the action, either to the meaning the actor gives his own action (subjective) and for the action of his fellow (intersubjective). Given these theories, this paper presents the divergent and convergent points between them, but above all, how records are complementary in the pursuit of understanding the meaning of social action. Besides the conceptual precepts, the paper discusses the construction and application of the model "ideal type" (TI) supported a Schutzian design.
\end{abstract}

KEYWORDS: Social action - sense. Max Weber - Understanding Sociology. Alfred Schutz - Understanding Phenomenology - The World of Life. Ideal type.

Em Tese, Florianópolis, v. 11, n. 1, jan./jun., 2014. ISSN: 1806-5023 


\section{Tmevista Eletrônica dos Pós Graduandos \\ é é em Sociologia Política da UFSC}

Recebido em: 14 de fevereiro de 2014

Aceito para publicação em: 08 de abril de 2014 